\title{
HABITAT RELATIONSHIPS OF GREAT GRAY OWL PREY IN MEADOWS OF THE SIERRA NEVADA MOUNTAINS
}

by

\author{
Ryan S. Kalinowski
}

A Thesis

Presented to

The Faculty of Humboldt State University

\author{
In Partial Fulfillment \\ Of the Requirements for the Degree \\ Masters of Science \\ In Natural Resources: Wildlife
}

August, 2012 



\begin{abstract}
Habitat Relationships of Great Gray Owl Prey in Meadows of the Sierra Nevada Mountains

Ryan Kalinowski
\end{abstract}

The great gray owl (Strix nebulosa) has been a state endangered species in California since 1980 because of low population size. Annual productivity of the great gray owl in California is thought to be largely dependent on vole (Microtus spp.) and pocket gopher (Thomomys spp., hereafter gopher) abundance, yet the factors influencing these prey populations have not been thoroughly investigated. The abundance of voles and gophers has been influenced by vegetation and cattle grazing in other regions, and many meadows are grazed within the breeding range of the great gray owl in the Sierra Nevada Mountains of California. Therefore I evaluated the influence of vegetation and cattle grazing on great gray owl foraging habitat by quantifying vole abundance, gopher abundance, and vegetative conditions in grazed and ungrazed meadows during owl nestling and fledgling stages. I surveyed 17 grazed and 15 ungrazed meadow sites in 2010, and 19 grazed and 19 ungrazed meadow sites in 2011. I found that vole presence was positively associated with plant sward height and corn lily (Veratrum californicum) dominance; vole abundance was weakly negatively associated with cattle grazing. Gopher abundance was negatively associated with site wetness, and positively associated with stem density, the frequency of forb presence, cattle grazing, and the dominance of corn lily. When managing meadows for great gray owl conservation, cattle grazing and vegetation should be monitored to accommodate the habitat relationships of both voles and gophers. Management of owl prey may be most efficient by prioritizing wet meadow sites for voles since gophers were not likely to be abundant in wet sites, and vole 
abundance has been correlated with moist soils in other studies. Therefore particularly in areas with moist soils, I recommend maintaining plant sward height commensurate with the habitat relationships of voles found in this study. 


\section{ACKNOWLEDGEMENTS}

I would like to thank Matthew D. Johnson, T. Luke George, Richard T. Golightly, and Adam C. Rich for their comments and suggestions that greatly improved this document. I also thank the U.S. Forest Service for employing me throughout this project, Crispin Holland for providing information on cattle grazing, Sarah Stock for coordinating research efforts in Yosemite National Park, Joe Medley for sharing his expertise on great gray owls, Anthony Desch and Humboldt State University for distributing sampling materials, Leanne M. Knutson for her domestic support, and Joseph LaManna for coordinating preliminary research. I thank Justin Demianew, George Prounis, Ben Vernasco, Jillian Soller, Jessica Clark, Pat Spielman, and Nicolette Nelson for their hard work and relentless dedication to this project. I also thank The Garden Club of America and the Cornell Lab of Ornithology for their financial support via the Frances M. Peacock Scholarship for Native Bird Habitat. 


\section{TABLE OF CONTENTS}

\section{Page}

ABSTRACT $\ldots \ldots \ldots \ldots \ldots \ldots \ldots \ldots \ldots \ldots \ldots \ldots \ldots \ldots \ldots \ldots \ldots \ldots \ldots \ldots \ldots \ldots$

ACKNOWLEDGMENTS $\ldots \ldots \ldots \ldots \ldots \ldots \ldots \ldots \ldots \ldots \ldots \ldots$

LIST OF TABLES $\ldots \ldots \ldots \ldots \ldots \ldots \ldots \ldots \ldots \ldots \ldots \ldots \ldots \ldots \ldots \ldots \ldots$

LIST OF FIGURES $\ldots \ldots \ldots \ldots \ldots \ldots \ldots \ldots \ldots \ldots \ldots \ldots \ldots \ldots$ viii

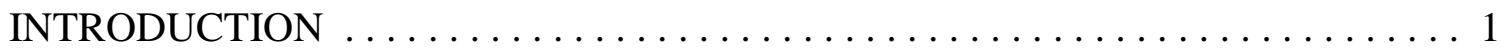

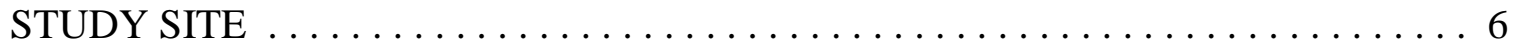

MATERIALS AND METHODS $\ldots \ldots \ldots \ldots \ldots \ldots \ldots \ldots \ldots \ldots \ldots$

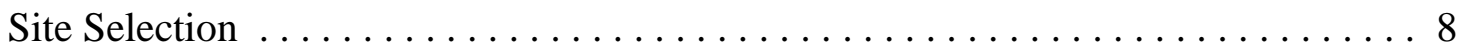

Vole and Gopher Abundance $\ldots \ldots \ldots \ldots \ldots \ldots \ldots \ldots \ldots \ldots$

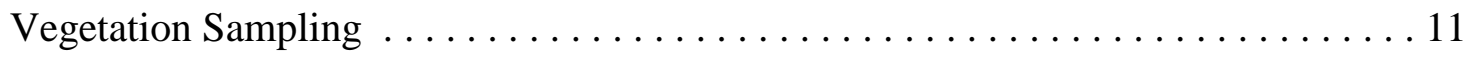

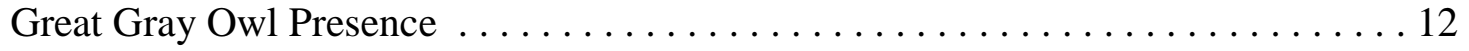

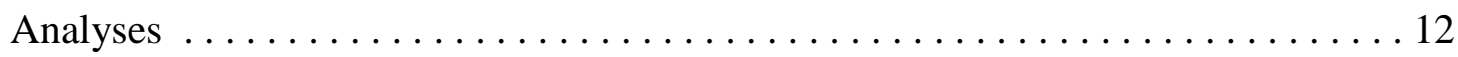

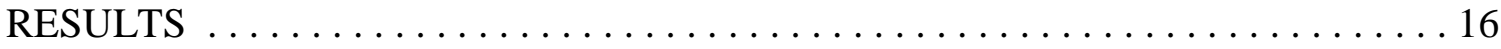

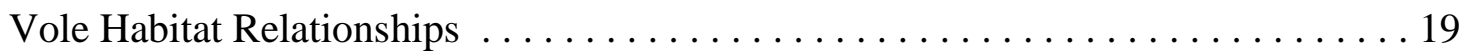

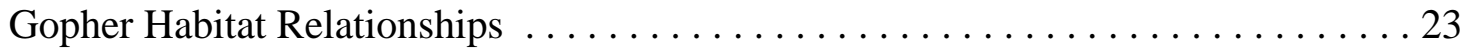

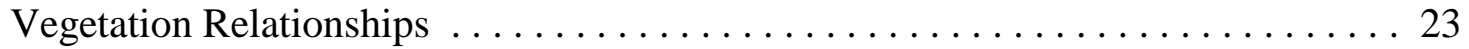

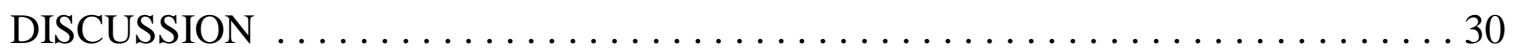

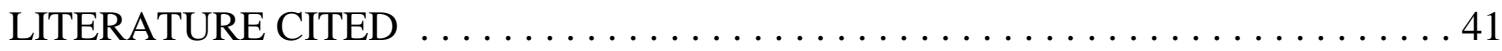




\section{LIST OF TABLES}

Table

Page

1 Best logistic regression model for predicting vole presence/absence at meadow sites in the Sierra Nevada Mountains, California, in 2010 and 2011. All 25 other candidate models had $\Delta \mathrm{AIC}_{c}$ greater than two ........... 20

2 Correct Classification Rates using three cut-points from the logistic regression model predicting vole presence/absence at meadow sites in the Sierra Nevada Mountains, California. Model-averaged coefficients from $k$-fold validation procedures were used to obtain predicted probabilities that were used to make classifications. The cut-point is the probability of presence where a value greater than or equal to the cut-point is considered presence and a value less than the cut-point is considered absence. Correct classification rate is the number of correct classifications out of the total number of classifications. All other rates are the number in a given classification category out of the total number of actual observations for that category. For example, the correct positive rate is the number of actual positives that were predicted as positives divided by the total number of actual positives . . . . . . . . . . . . 22

3 Best linear regression model for predicting vole abundance at meadow sites where voles were present in the Sierra Nevada Mountains, California, in 2010 and 2011. All 25 other candidate models had $\Delta \mathrm{AIC}_{c}$ greater than two . . . . . 24

4 Best linear regression models for predicting gopher abundance at meadow sites in the Sierra Nevada Mountains, California, in 2010 and 2011. All 20 other candidate models had $\Delta \mathrm{AIC}_{c}$ greater than two . . . . . . . . . 25-26

5 Model-averaged linear regression model for predicting gopher abundance at meadow sites in the Sierra Nevada Mountains, California, in 2010 and 2011. Four candidate models that had $\Delta \mathrm{AIC}_{c}$ less than two were included in the model average (see Table 4 for original models) . . . . . . . . . . . . . 27

6 Means plus or minus one standard error for vegetation, wetness, and soil temperature at grazed and ungrazed meadow sites in the Sierra Nevada Mountains, California, in 2010 and $2011 \ldots \ldots \ldots \ldots$. . . . . . . . . 29 


\section{LIST OF FIGURES}

Figure

Page

1 Map displaying sampling locations (circles) in Stanislaus National Forest and Yosemite National Park in the Sierra Nevada Mountains, California, 2010

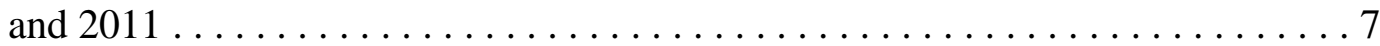

2 Number of individual voles captured per web at meadow sites in the Sierra Nevada Mountains, California. Abundance estimates displayed are from 17 grazed and 15 ungrazed sites in 2010 and 19 grazed and 19 ungrazed sites in

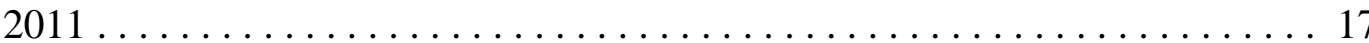

$3 \quad$ Number of gophers per plot estimated from fresh mounds at meadow sites in the Sierra Nevada Mountains, California. Abundance estimates displayed are from 17 grazed and 15 ungrazed sites in 2010 and 19 grazed and 19 ungrazed

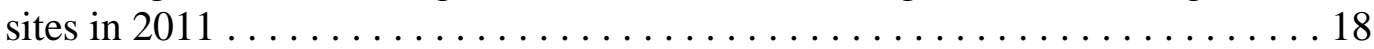

4 Receiver Operating Characteristic (ROC) curve from the top model for predicting vole presence/absence. Model-averaged coefficients from $k$-fold validation procedures were used to obtain predicted probability of vole presence values used in the ROC analysis. Sensitivity is the proportion of actual presence cases correctly predicted as presence, while one minus specificity is the proportion of actual absence cases predicted as presence

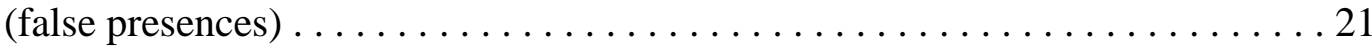

5 The influence of sward height on predicted probability of vole presence at corn lily dominated and non-corn lily dominated meadow sites in the Sierra Nevada Mountains, California, 2010 and 2011. Model-averaged coefficients from $k$-fold validation procedures and observed sward heights were used to obtain predicted values . . . . . . . . . . . . . . . . . . 34

6 The influence of site wetness on predicted gopher abundance at meadow sites in the Sierra Nevada Mountains, California, in 2010 and 2011. Model-averaged coefficients from competitive linear regression models $\left(\Delta \mathrm{AIC}_{c}\right.$ less than two) were used with observed wetness values to obtain predicted abundance. All other variables from the model-average were held constant at their respective

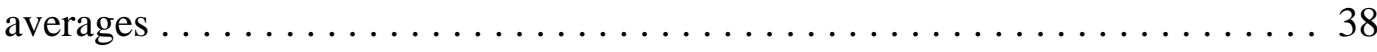




\section{INTRODUCTION}

The great gray owl (Strix nebulosa) has been listed as a state endangered and sensitive species in California since 1980 due to low population size and high sensitivity to human disturbance (United States Department of Agriculture 2004, California Department of Fish and Game 2011). Current population estimates range from 73 to just over 100 individuals for Yosemite and adjacent National Forests, and only 123 to possibly 200 or 300 for the entire Sierra Nevada Mountains (hereafter Sierra Nevada) (Winter 1986, Greene 1995, Sears 2006, Hull et al. 2010). Great gray owls in the Sierra Nevada have continued to exhibit low annual productivity for reasons that are inconclusive, but may include limited prey abundance (Greene 1995, Beck and Winter 2000). The abundance of related prey species in other regions has been influenced by vegetation and cattle grazing, and many meadows in the Sierra Nevada are grazed (Jacob and Hempel 2003, Schmidt et al. 2005, Johnson and Horn 2008). Despite this, the influences of vegetation and cattle grazing on prey abundance within the breeding range of great gray owls in the Sierra Nevada have not been thoroughly investigated.

In California and southern Oregon, great gray owls have relied heavily on subalpine meadows with sufficient densities of voles (Microtus spp.) and pocket gophers (Thomomys spp., hereafter gopher) for survival and reproduction (Winter 1986, Greene 1995, van Riper and van Wagtendonk 2006). Voles and gophers have accounted for over $94 \%$ of pellet biomass in California in most years (Winter 1986, Reid 1989). Vole populations have typically undergone two to five year population cycles, and great gray owls have not reproduced well when vole and gopher populations were low (Hilden and 
Helo 1981, Winter 1986, Smolen and Keller 1987, Franklin 1988, Reid 1989, Bull and Henjum 1990, Greene 1995).

The collective importance of voles and gophers to great gray owl productivity in the Sierra Nevada has been well documented, but the relative importance of voles versus gophers is not fully understood (Winter 1981, 1982, and 1986, Greene 1995, Reid 1989). A two-year study in the Sierra Nevada found that owl reproductive success was correlated with the proportion of voles found in owl pellets (Winter 1981 and 1982). Winter (1981, 1982, and 1986) suggested that vole abundance may have been the primary determinant of owl productivity, but gopher abundance may have been important for owl survival when voles were less abundant. Reid (1989) found that owl reproductive success in Yosemite was associated with the total biomass of voles and gophers in owl pellets, not the biomass of one or the other. Greene (1995) found that owl presence and reproduction in the Sierra Nevada were positively associated with vole habitat (higher plant cover, plant height, and soil moisture) and abundance. Greene (1995) also found that owl presence was negatively associated with gopher abundance. Though most results have suggested that great gray owl productivity was associated primarily with vole abundance and habitat, gophers appeared to be important prey particularly when vole abundance was low.

Several vole and gopher species in the Sierra Nevada have been highly associated with meadows, yet within-meadow habitat associations have been different. The three vole species within great gray owl foraging habitat in the Sierra Nevada are the montane vole (Microtus montanus), long-tailed vole (Microtus longicaudus), and California vole (Microtus californicus) (Reid 1989, Moritz et al. 2008). All three species have been 
positively associated with moist soils, vegetation height, cover, and density (Smolen and Keller 1987, Sera and Early 2003, Getz et al. 2005). The gopher species are the mountain pocket gopher (Thomomys monticola), Botta's pocket gopher (Thomomys bottae), and possibly the northern pocket gopher (Thomomys talpoides). These species have generally been found in drier, softer soils with less vegetative cover relative to habitat used by voles (Ingles 1952, Greene 1995, Jones and Baxter 2004). Despite these differences, voles and gophers in the Sierra Nevada have regularly co-occurred in the same meadows (Winter 1986, Greene 1995).

Cattle grazing has diminished vegetation height, cover, and vole abundance in several studies (Jacob and Hempel 2003, Schmidt et al. 2005, Johnson and Horn 2008, Johnston and Anthony 2008). Rapid declines in vole abundance, female body weight, female survivorship, and recruitment have been associated with grazing and experimental reductions in standing biomass (Peles and Barrett 1996, Klaus et al. 1999, Jacob and Hempel 2003). Eight months after initiation of grazing, Johnson and Horn (2008) observed drastic declines in vole abundance, vegetation height, and cover in a coastal grassland. Birney et al. (1976) hypothesized that lack of vegetation cover may increase the amount of time between vole population peaks and reduce vole population density.

Several studies have attempted to identify vole habitat relationships in the Sierra Nevada based on sign (e.g., Winter 1986, Reid 1989, Greene 1995), but sign indices for voles have been unreliable due to low detection rates and misidentification (Gervais 2010). Sign indices for voles may have also been biased by species composition because long-tailed voles have not usually constructed runways, and runways have been relatively 
detectable sign when made by other species (including the montane vole; Ingles 1965, Johnson and Johnson 1982, Smolen and Keller 1987).

The influence of cattle grazing on gophers has been less clear. Indices of gopher abundance have decreased with grazing in some studies (e.g., Hunter 1991) and increased with grazing in others (e.g., Powers et al. 2011). Gopher abundance may be positively associated with cattle grazing because grazing can lead to drier soil, lower water table height, and quicker snow melt due to less vegetative cover (Gifford and Hawkins 1978, Armour et al. 1991). Conversely, cattle grazing may cause unfavorable alterations in plant species composition and decrease gopher burrowing ability due to soil compaction (Ingles 1952, Gifford and Hawkins 1978, Armour et al. 1991). A study in the Sierra Nevada found gopher abundance was higher in grazed meadows (Powers et al. 2011).

Though cattle grazing has been suspected to be a key factor influencing prey abundance, and therefore owl reproduction, the actual effects on voles, gophers, and vegetation have not been thoroughly evaluated. Furthermore, vegetative conditions that yield high vole and gopher abundance in meadows of the Sierra Nevada are not fully understood. Therefore I quantified vole abundance, gopher abundance, and vegetative conditions in grazed and ungrazed meadows within suitable great gray owl foraging habitat in the Sierra Nevada. My objectives were to determine: 1) vegetative conditions that correlate with vole and gopher abundance, and 2) the influence of grazing on vole abundance, gopher abundance, and vegetative conditions. The goal of this research was to obtain the information necessary for improving and expanding suitable great gray owl foraging habitat. 
Based on findings from other studies on voles, I hypothesized that voles would benefit from cover from predators, and predicted greater abundance and presence in sites with higher vegetation height, cover, and density (Smolen and Keller 1987, Sera and Early 2003). From the results of other studies on grazing, I hypothesized that overall vegetation and vole numbers would be reduced by cattle grazing (Schmidt et al. 2005, Johnson and Horn 2008). If this hypothesis was supported, I expected greater vegetation height, cover, and density in ungrazed sites, as well as a positive association between voles and ungrazed sites (Greene 1995, Johnson and Horn 2008). Based on recent data from the Sierra Nevada (Powers et al. 2011), I hypothesized that gophers would be positively affected by grazing, and predicted a positive correlation between gopher abundance and grazed sites. 


\section{STUDY SITE}

I conducted this study in meadows in Stanislaus National Forest (south of highway 4) and Yosemite National Park (north of Glacier Point Road) on the western slopes of the central Sierra Nevada in California, USA (Figure 1). In Stanislaus National Forest, I surveyed meadow sites in cattle grazing allotments (hereafter grazed) and meadow sites not in cattle grazing allotments (hereafter ungrazed); all meadow sites in Yosemite National Park were ungrazed. Vegetation in these montane meadows included various species of grasses, sedges, rushes, forbs, and willows (Potter 2005). Meadow plants were identified to group (grass, sedge, rush, or forb), genus, and/or species. Surrounding vegetation was typically mixed conifer forest with species such as Jeffery Pine (Pinus jefferyi), Lodgepole Pine (Pinus contorta), Pondorosa Pine (Pinus ponderosa), Sugar Pine (Pinus lambertiana), White Fir (Abies concolor), Red Fir (Abies magnifica), and Incense Cedar (Calocedrus decurrens). At 1430 m elevation, average minimum to average maximum temperature was 0 to $10^{\circ} \mathrm{C}$ in November through April and 10 to $25^{\circ} \mathrm{C}$ in May through October. Average precipitation was $136 \mathrm{~cm}$ in November 2009 to October 2010 and $177 \mathrm{~cm}$ in November 2010 to October 2011. Precipitation occurred mostly in the form of snow in November through April (Western Regional Climate Center 2012). 


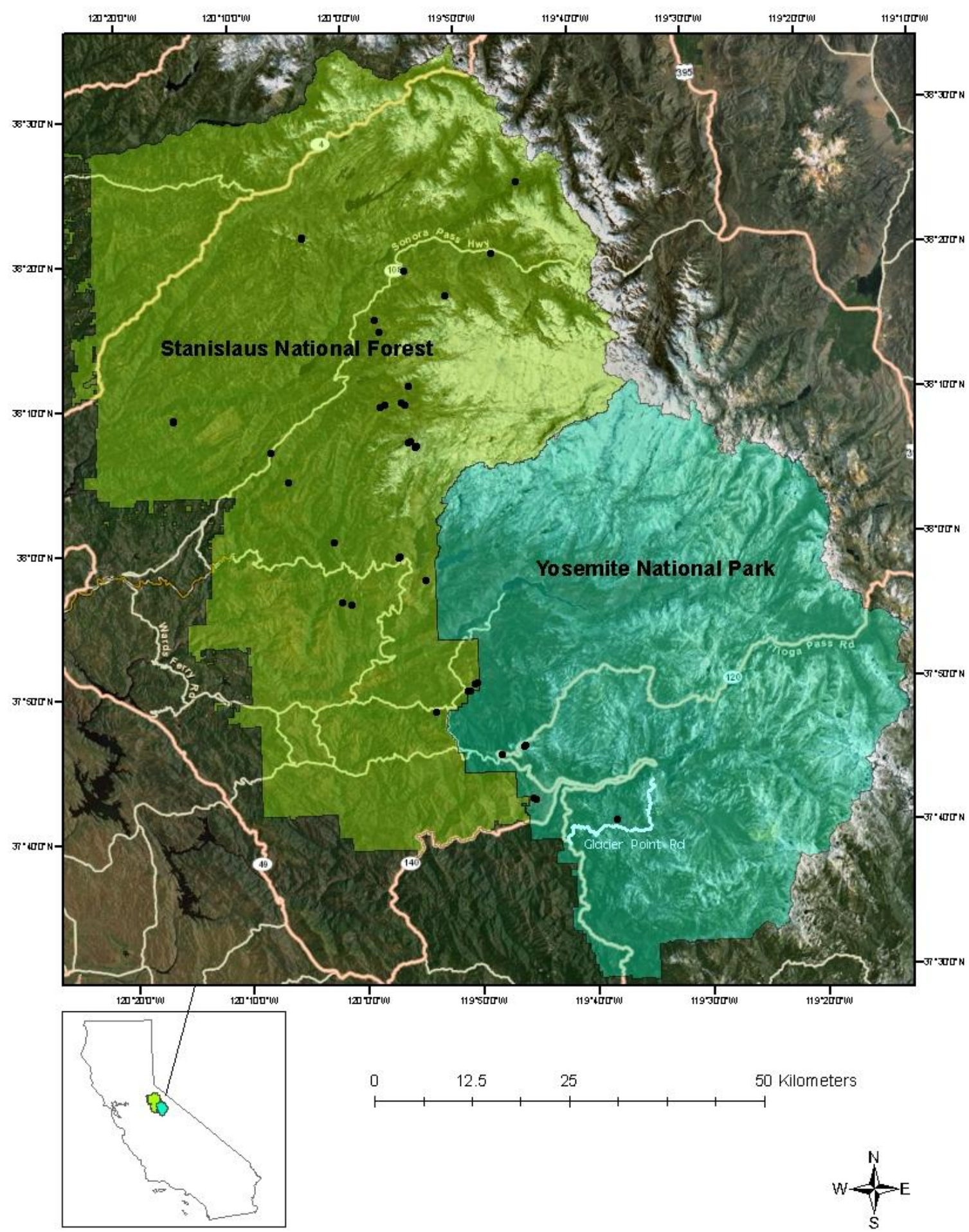

Figure 1. Map displaying sampling locations (circles) in Stanislaus National Forest and Yosemite National Park in the Sierra Nevada Mountains, California, 2010 and 2011. 


\section{MATERIALS AND METHODS}

\section{$\underline{\text { Site Selection }}$}

I determined which meadows could be included in this study based on great gray owl foraging habitat selection. All meadows selected were: 1) on the western slope of the Sierra Nevada Mountain crest, 2) greater than four ha in size or part of a complex greater than four ha in size, and 3) between $1100 \mathrm{~m}$ and $2300 \mathrm{~m}$ elevation to match great gray owl breeding elevation range and to minimize plant community differences (Beck and Winter 2000). In addition, all meadows were within $700 \mathrm{~m}$ of a road for accessibility.

In 2010, 11 ungrazed sites in Stanislaus National Forest that met the above criteria were selected randomly and matched with 13 grazed sites that were nearest in spatial proximity and elevation to the ungrazed sites. There were two more grazed sites surveyed than ungrazed sites because a meadow that was believed to be ungrazed was determined to be grazed upon further evaluation. From all suitable sites in Yosemite National Park, four ungrazed sites were selected randomly and paired with four sites in Stanislaus that where most similar in elevation and location to the Yosemite sites. I surveyed all sites from 2010 again in 2011, and added four ungrazed sites in Yosemite and two grazed sites in Stanislaus in 2011. Meadows were identified in ArcGIS (version 9.2) using meadow layers provided by the U.S. Forest Service (updated 2010) and National Park Service (1997). There was no significant difference in elevation between grazed and ungrazed sites $(t=0.43 ; \mathrm{df}=37 ; P=0.670)$.

Nine meadows (five ungrazed and four grazed) were large enough to contain two sampling sites each. Sites within meadows were greater than $200 \mathrm{~m}$ apart and were treated as independent because: 1) home range movements of closely related vole species 
have been less than $100 \mathrm{~m}$ (Getz et al. 1994), 2) gopher abundance sampling was completed within a 24 hour period and the average daily movements of Botta's pocket gophers have been less than $38 \mathrm{~m}$ (Jones and Baxter 2004), 3) no marked animals were ever found in more than one site, and 4) there were often detectable differences in vegetation, wetness, and small mammal abundances between sites.

In total, I surveyed 38 meadow sites (19 grazed and 19 ungrazed) for small mammals, vegetation, and other meadow characteristics. I surveyed one grazed and one ungrazed site or two grazed and two ungrazed sites simultaneously each week (one week per site per year) from mid-May to late July (2010) or early August (2011). There was one week when three grazed sites were surveyed with one ungrazed site because I was originally told a grazed site was ungrazed. I surveyed each site six days later in 2011 than in 2010 in an attempt to match the timing after snowmelt (there was greater snow depth in 2011; Western Regional Climate Center 2012). Each year yielded 11 weeks of surveys that coincided with great gray owl nestling and fledgling stages (Bull and Henjum 2000).

\section{$\underline{\text { Vole and Gopher Abundance }}$}

I used a trapping web in each site to estimate vole abundance (Parmenter 2003, Buckland et al. 2004). I located the web center by walking from the center of the meadow along a randomly selected azimuth (using a random number generator) to a point $30 \mathrm{~m}$ from the forest edge. Starting $2 \mathrm{~m}$ from the center, I established 12 spokes (trap-lines) of Sherman live-traps (H.B. Sherman Traps $3 \times 3$ or $3.5 \times 9$ or 10) with eight traps spaced $4 \mathrm{~m}$ apart per spoke giving a total of 96 traps per web. With this layout, traps were within $61 \mathrm{~m}$ of the meadow edge which was found to be the maximum 
distance a great gray owl would fly from a meadow edge perch to hunt prey (Winter 1986).

Traps were always left open and were checked within the two hours prior to sunset and again within three hours after sunrise for five consecutive days. I baited traps with rolled oats and peanut butter and added polyester batting for insulation. Small mammals that were captured were marked with a unique monel ear-tag (National Band and Tag Company model 1005-1). Trap location, species, weight (g), sex, reproductive status (breeding adult defined as pregnant, lactating, or perforate vagina opening for females and scrotal testes for males), and presence of wounds (number and location) were recorded for each capture. Immediately after processing, I released small mammals at the site of capture.

Gophers were not readily trappable, so I indexed gopher abundance by counting the number of fresh gopher mounds within three $10 \mathrm{~m}$ by $100 \mathrm{~m}$ belt transects per site (Powers et al. 2011). I centered the middle belt transect on the trapping web spoke that was most parallel to the meadow edge. The two other belt transects were parallel to the middle belt with $10 \mathrm{~m}$ spacing between belt edges. To obtain estimates, I walked the belt until fresh evidence was found, recorded the evidence as one gopher, and walked $11 \mathrm{~m}$ before counting any other evidence as another gopher. I chose this distance because Ingles (1952) found that the average female mountain pocket gopher territory size in summer was equivalent to an $11 \mathrm{~m}$ diameter circle. Male territories were smaller and gophers were solitary except when mating, so $11 \mathrm{~m}$ spacing between observations allowed me to calculate a conservative index of gopher abundance (Powers et al. 2011). All of the procedures described for sampling small mammals were approved under 
Humboldt State University's Institutional Animal Care and Use Committee (08/09.W.65.A).

\section{Vegetation Sampling}

To quantify vegetative condition, I measured the following at every third trap and at the beginning and end of each gopher belt (42 locations) during the first two days of trapping: 1) maximum vegetation height within the four outer corners of a $56 \mathrm{~cm}$ by 25 $\mathrm{cm}$ frame (frame is divided into twenty-five $10 \mathrm{~cm}$ squares), 2) proportion of vegetation cover by recording the number of times rooted vegetation or thatch was directly beneath each of the 16 intersections within the vegetation frame and dividing by 16,3 ) vegetation stem density by counting the number of rooted plants within a $5 \mathrm{~cm}$ by $3.8 \mathrm{~cm}$ rectangle, 4) vegetation height/density using a sward stick ( $170 \mathrm{~g} 30 \mathrm{~cm}$ by $30 \mathrm{~cm}$ plate, with a meter stick placed through a slit in the middle. I dropped the plate from $80 \mathrm{~cm}$ and recorded the height (in $\mathrm{mm}$ ) where the plate rested as sward height), 5) presence or absence of grass, sedge, rush, and forb in the center square of the vegetation frame, and 6) wetness. I determined wetness by touch with the following definitions: dry when no moisture other than morning dew was detected, moist when soil was wet enough to clump and stick to fingers, saturated when water bubbled up when soil was depressed with fingers, and flooded when water was present above the soil surface. For each variable, I averaged the values from the 42 locations at each site for analyses.

I assessed plant species composition by recording the abundance of each species in the center square of the vegetation frame at 16 locations (the fifth trap from the center on each of the 12 spokes (trap-lines) and at the start and end of each gopher belt). Soil temperature was measured by inserting a soil thermometer $10 \mathrm{~cm}$ below the soil surface 
three to five hours after sunrise at four locations on the trapping web (the sixth trap from the center on every third spoke). I averaged the four soil temperature measurements in each site. All vegetation measurements were $10 \mathrm{~cm}$ toward the web center from the associated trap location. In each meadow site, I visually assessed if corn lily (Veratrum californicum) was the spatially dominant plant for the site.

\section{Great Gray Owl Presence}

I obtained great gray owl presence/absence and general reproductive data for five meadows (nine sites) in 2010 and seven meadows (11 sites) in 2011 from the U.S. Forest Service Pacific Southwest Research Station; this group was locating owls with auditory playbacks, stand searches, and feather searches from April to August in 2010 and 2011. I surveyed the remaining meadows by conducting one daytime circum-meadow search looking for owls, feathers, and pellets, and two evening observations watching and listening for owls for ten minutes.

\section{$\underline{\text { Analyses }}$}

I indexed vole abundance using Minimum Number Alive, which was the number of individuals captured in a trapping web (web area $=2827 \mathrm{~m}^{2}$ ). Initially, I planned to estimate vole density using program DISTANCE, however, this type of estimation procedure would not perform well with the low capture and recapture rates I obtained in this study. Minimum Number Alive may more accurately represent population density when recapture rates are low and the number of animals captured is small (White et al. 1982, McKelvey and Pearson 2001). I indexed gopher abundance as the number of fresh gopher mounds tallied in the three $10 \mathrm{~m}$ by $100 \mathrm{~m}$ belts (total plot area $=3000 \mathrm{~m}^{2}$ ) at each site. 
I used twenty-six logistic regression models ranked with Akaike's Information Criterion adjusted for small sample size $\left(\mathrm{AIC}_{c}\right)$ to evaluate whether vegetation variables (cover, sward height, stem density, maximum vegetation height, corn lily dominance, and the probabilities of grass, sedge, rush, or forb presence), wetness, grazing status, year, or elevation influenced the presence or absence of voles at a site (Burnham and Anderson 2002). The presence or absence of voles was used to determine vole habitat relationships on all sites because abundance data were not normally distributed when all sites were included, even after transformations. I tested the top logistic regression model (all other models had $\Delta \mathrm{AIC}_{c}$ greater than two) post-hoc using $k$-fold partitioning $(k=7)$ and a Receiver Operating Characteristic (ROC) curve (Fielding and Bell 1997). In addition to the logistic regression models, I used twenty-six linear regression models ranked with $\mathrm{AIC}_{c}$ to evaluate if the variables (same variables as the logistic regression models) influenced vole abundance at sites were voles were present.

I used twenty-one multiple linear regression models ranked with $\mathrm{AIC}_{c}$ to determine if vegetation variables (cover, sward height, stem density, maximum vegetation height, corn lily dominance, and the probabilities of grass, sedge, rush, or forb presence), wetness, soil temperature, grazing status, year, or elevation influenced gopher abundance. I model-averaged the coefficients, standard errors, and 95 percent confidence intervals from competitive models ( $\triangle \mathrm{AIC}_{c}$ less than two) for multi-model inference (Burnham and Anderson 2002).

I assessed normality and equal variance assumptions for linear regression analyses visually from a residual versus fitted values plot. To meet normality assumptions, I transformed sward height, stem density, maximum vegetation height, and the probability 
of rush presence using the natural $\log (\mathrm{x}+(1 / 6))$, and gopher abundance using the square root of the observed values.

I selected variable combinations for all modeled relationships prior to analyses using insights from the scientific literature and my hypotheses as baseline information. I did not include maximum vegetation height in any models with vegetation cover and or sward height because the correlation coefficient $(r)$ was greater than 0.6. I treated years as independent in all regression analyses (logistic and linear) because there were considerable differences in the abundances of both voles and gophers at the same site between years.

I compared vegetation cover, sward height, vegetation stem density, and wetness between grazed and ungrazed sites, and between years, using repeated measures MANCOVA (Multivariate Analysis of Covariance). Elevation was a covariate in this analysis. I transformed sward height and stem density using the natural $\log (\mathrm{x}+(1 / 6))$ to meet normality assumptions. I did not include the probabilities of grass, sedge, rush, and forb presence because a multivariate normal distribution could not be achieved. I did not include maximum vegetation height because it was highly correlated $(r>0.6)$ with cover and sward height. Only repeated sites could be used, so I did not include the six sites that were new in 2011 in the repeated measures MANCOVA. I tested for equal variance using Levene's Test and Box's Test of Equality of Covariance Matrices, and I assessed normality visually from a normal probability plot. To determine if the frequency of corn lily dominance differed between grazed and ungrazed meadows, I used a chi-square test. I reported means and coefficients plus or minus one standard error (SE). I determined significance at $\alpha$ equals 0.05 for the repeated measures MANCOVA results 
except for the univariate comparisons where I used a Bonferroni adjustment. There were four response variables in the repeated measures MANCOVA, therefore I determined significance at $\alpha=0.013$. I performed all analyses using program $\mathrm{R}$ version 2.14 .0 except the repeated measures MANCOVA which was conducted in PASW Statistics 18. 


\section{RESULTS}

From 17 May to 30 July 2010, I captured 51 individual voles and estimated 290 gophers from fresh mounds in 17 grazed and 15 ungrazed meadow sites. Voles were present in 12 of 32 sites ( 38 percent), and vole abundance ranged from 0 to 13 voles per web and averaged $1.59( \pm 0.57)$ voles per web. Gophers were present in 29 of 32 sites (91 percent), and gopher abundance ranged from 0 to 25 gophers per plot and averaged $9.06( \pm 1.21)$ gophers per plot.

From 23 May to 5 August 2011, I captured 66 individual voles and estimated 131 gophers from fresh mounds in 19 grazed and 19 ungrazed meadow sites. Voles were present in 14 of 38 sites ( 37 percent), and vole abundance ranged from 0 to 11 voles per web and averaged $1.74( \pm 0.52)$ voles per web. Gophers were present in 32 of 38 sites (84 percent), and gopher abundance ranged from 0 to 12 gophers per plot and averaged $3.45( \pm 0.49)$ gophers per plot. Voles and gophers co-occurred in 9 of 32 sites (28 percent) where at least one vole or gopher was present in 2010 and 13 of 33 sites (39 percent) in 2011.

Mean vole abundance for 2010 and 2011 combined was $1.50( \pm 0.45)$ voles per web in grazed sites and $1.85( \pm 0.63)$ voles per web in ungrazed sites (Figure 2). Mean gopher abundance for 2010 and 2011 combined was 7.31 ( \pm 1.07$)$ gophers per plot in grazed sites and $4.65( \pm 0.83)$ gophers per plot in ungrazed sites (Figure 3). Of the voles captured, 51 of 117 (44 percent) were montane voles and 66 of 117 (56 percent) were long-tailed voles. These two vole species co-occurred in 5 of the 26 cases (19 percent) when at least one species was present. Though gopher abundance was estimated from fresh mounds, I also captured four gophers in traps; three were mountain pocket gophers 


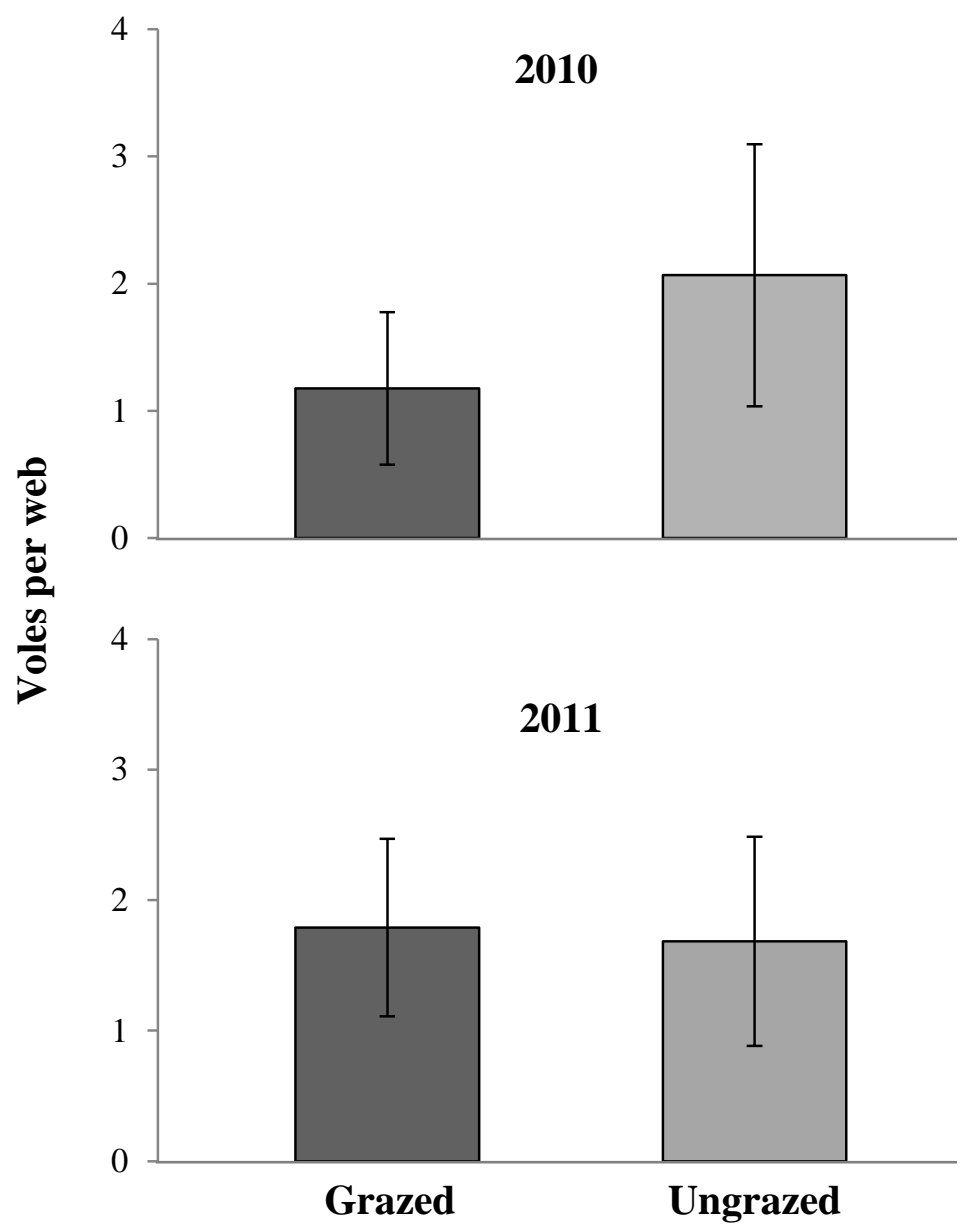

Figure 2. Number of individual voles captured per web at meadow sites in the Sierra Nevada Mountains, California. Abundance estimates displayed are from 17 grazed and 15 ungrazed sites in 2010 and 19 grazed and 19 ungrazed sites in 2011. 


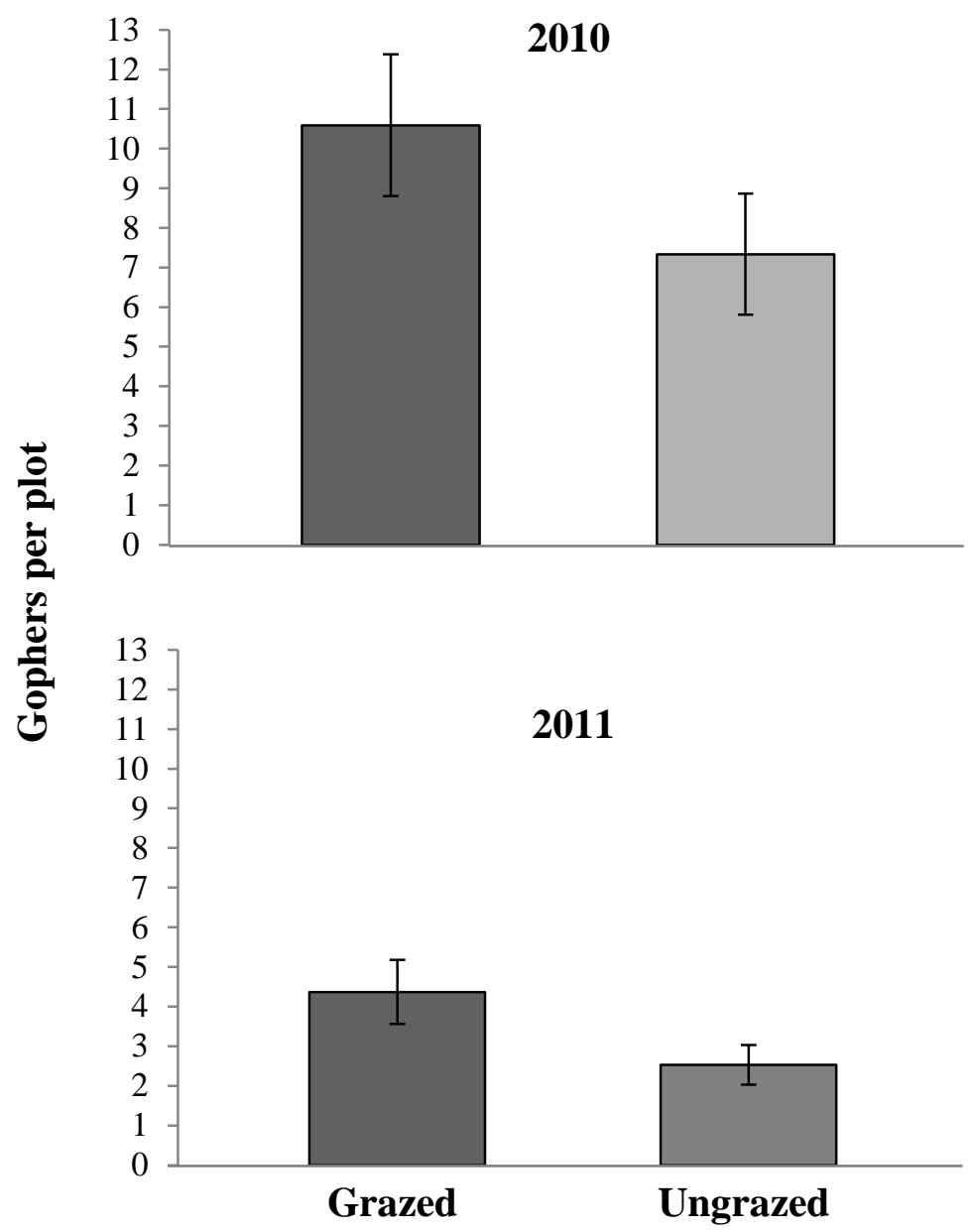

Figure 3. Number of gophers per plot estimated from fresh mounds at meadow sites in the Sierra Nevada Mountains, California. Abundance estimates displayed are from 17 grazed and 15 ungrazed sites in 2010 and 19 grazed and 19 ungrazed sites in 2011. 
and one could not be determined. I did not detect any great gray owls in 2010. In 2011, I observed two great gray owls roosting in two different meadows (one owl per meadow; both meadows had two sampling sites), and found numerous feathers in one of these meadows. The Pacific Southwest Research Station determined great gray owl presence from feathers or auditory playbacks in five study meadows (nine sampling sites) in 2010 and in five study meadows (eight sampling sites) in 2011 (in addition to the meadows where I detected owls). Because my survey methods and effort were different from the Pacific Southwest Research Station, great gray owl data were not analyzed statistically.

\section{$\underline{\text { Vole Habitat Relationships }}$}

The top model for vole presence/absence included a positive association with the natural $\log$ of sward height $(\beta=2.75 \pm 0.84)$ and a positive association with corn lily dominance $(\beta=1.69 \pm 0.70 ;$ Table 1$)$. The 95 percent confidence interval for coefficients in the top model did not include zero. This model accounted for 0.41 of the total $\mathrm{AIC}_{c}$ weight and explained 29.28 percent of the null deviance. All other models were greater than two $\mathrm{AIC}_{c}$ from the top model so they were considered less competitive. The area under the ROC curve after $k$-fold partitioning was 0.84 ( \pm 0.05 ; Figure 4$)$. The model performed better at predicting the number of absences out of the total actual absences than the number of positives out of the total actual positives (Table 2). Average sward height (actual sward height, not transformed) in sites where voles were present was $143( \pm 14)$ $\mathrm{mm}$ while average sward height in sites where voles were absent was $84( \pm 7) \mathrm{mm}$. Voles were present in 12 of the 17 cases (71 percent) where corn lily was dominant and 14 of the 53 cases (26 percent) where corn lily was not dominant.

The top model for vole abundance in sites with voles present included a negative 
Table 1. Best logistic regression model for predicting vole presence/absence at meadow sites in the Sierra Nevada Mountains, California, in 2010 and 2011. All 25 other candidate models had $\Delta \mathrm{AIC}_{c}$ greater than two.

\begin{tabular}{|c|c|c|c|c|c|c|c|c|}
\hline \multirow[b]{2}{*}{ Variable } & \multirow[b]{2}{*}{$K^{\mathrm{a}}$} & \multicolumn{5}{|c|}{$\%$ Deviance } & \multicolumn{2}{|c|}{$95 \% \mathrm{CI}$} \\
\hline & & $\Delta \mathrm{AIC}_{c}{ }^{\mathrm{b}}$ & $\mathrm{w}_{i}^{\mathrm{c}}$ & Explained & Coeff & SE & Lower & Upper \\
\hline & 3 & 0.00 & 0.41 & 29.28 & & & & \\
\hline Intercept & & & & & -13.62 & 3.96 & -21.39 & -5.85 \\
\hline LN sward height & & & & & 2.75 & 0.84 & 1.10 & 4.40 \\
\hline $\begin{array}{l}\text { Corn lily } \\
\text { dominance }\end{array}$ & & & & & 1.69 & 0.70 & 0.31 & 3.07 \\
\hline
\end{tabular}

${ }^{\mathrm{a}} K=$ number of parameters

${ }^{\mathrm{b}} \Delta \mathrm{AIC}_{c}=$ difference between $\mathrm{AIC}_{c}$ of the model specified and the model with the lowest $\mathrm{AIC}_{c}$

${ }^{\mathrm{c}} \mathrm{W}_{i}=$ Akaike weight. Indicates the probability that the model specified is the best predictive model within the set of candidates 


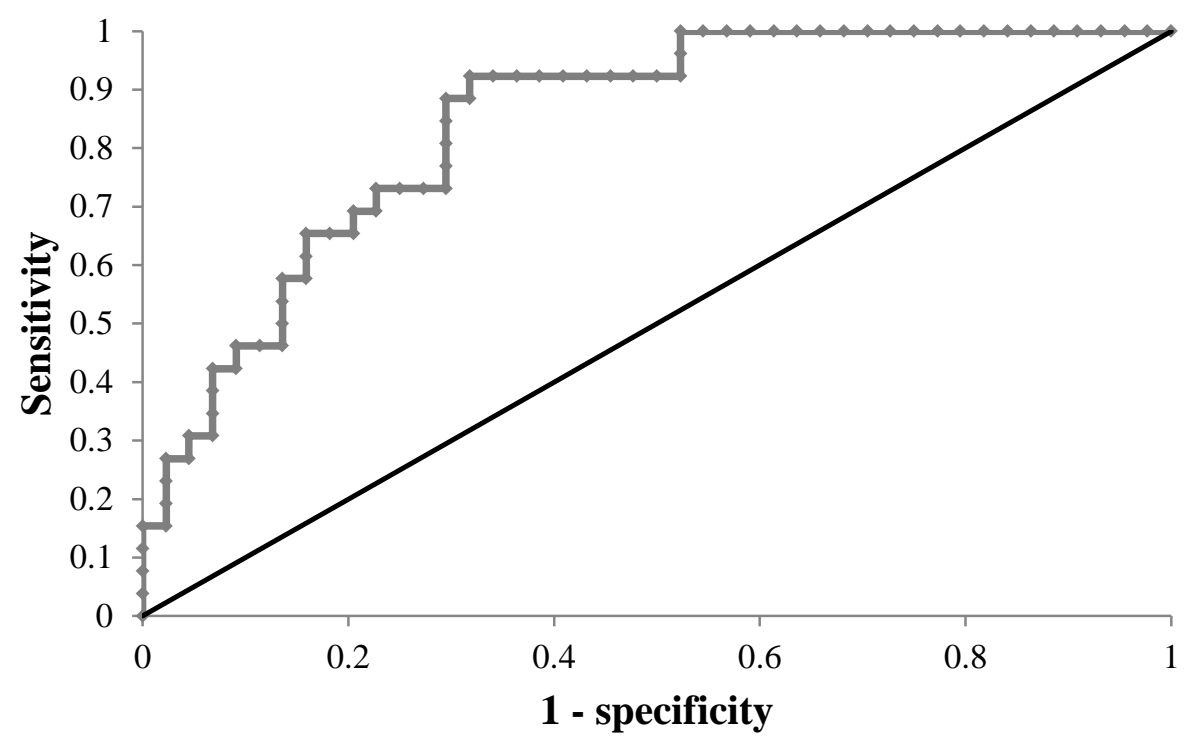

Figure 4. Receiver Operating Characteristic (ROC) curve from the top model for predicting vole presence/absence. Model-averaged coefficients from $k$-fold validation procedures were used to obtain predicted probability of vole presence values used in the ROC analysis. Sensitivity is the proportion of actual presence cases correctly predicted as presence, while one minus specificity is the proportion of actual absence cases predicted as presence (false presences). 
Table 2. Correct Classification Rates using three cut-points from the logistic regression model predicting vole presence/absence at meadow sites in the Sierra Nevada Mountains, California. Model-averaged coefficients from $k$-fold validation procedures were used to obtain predicted probabilities that were used to make classifications. The cut-point is the probability of presence where a value greater than or equal to the cut-point is considered presence and a value less than the cut-point is considered absence. Correct classification rate is the number of correct classifications out of the total number of classifications. All other rates are the number in a given classification category out of the total number of actual observations for that category. For example, the correct positive rate is the number of actual positives that were predicted as positives divided by the total number of actual positives.

\begin{tabular}{lccc}
\hline & \multicolumn{3}{c}{ Cut-point } \\
\cline { 2 - 4 } Classification & 0.5 & 0.7 & 0.9 \\
\hline Correct Classification Rate & 0.76 & 0.73 & 0.69 \\
Correct Positive Rate & 0.58 & 0.42 & 0.19 \\
False Negative Rate & 0.42 & 0.58 & 0.81 \\
Correct Negative Rate & 0.86 & 0.91 & 0.98 \\
False Positive Rate & 0.14 & 0.09 & 0.02 \\
\hline
\end{tabular}


association with grazing $(\beta=-2.13 \pm 1.49)$ and accounted for 0.28 of the total $\mathrm{AIC}_{c}$ weight (Table 3). However, this model only explained 7.79 percent of the null deviance and the 95 percent confidence interval for the coefficient of grazing included zero. All other models were greater than two $\mathrm{AIC}_{c}$ from the top model.

\section{Gopher Habitat Relationships}

Four candidate models for gopher abundance had $\Delta \mathrm{AIC}_{c}$ less than two (Table 4), so coefficients, standard errors, and the 95 percent confidence intervals were modelaveraged. The model-average showed that gopher abundance was negatively associated with site wetness $(\beta=-1.38 \pm 0.17)$, and positively associated with stem density $(\beta=0.39$ $\pm 0.29)$, frequency of forb presence $(\beta=2.10 \pm 1.24)$, grazing $(\beta=0.25 \pm 0.22)$, and the dominance of corn lily $(\beta=0.41 \pm 0.25$; Table 5$)$. The model-averaged 95 percent confidence interval for the coefficient of wetness did not include zero; the modelaveraged 95 percent confidence interval for all other variables included zero. The top four models accounted for 0.63 cumulative $\mathrm{AIC}_{c}$ weight and the model-averaged percent null deviance explained was 52.35 .

\section{Vegetation Relationships}

Meadow vegetation variables (cover, sward height, and stem density) and meadow wetness were not significantly different between grazed and ungrazed sites $(F=1.60$; df $=4,26 ; P=0.204)$, but were significantly different between years $(F=10.83 ; \mathrm{df}=4,26$; $P=0.000)$ and by elevation $(F=2.82 ; \mathrm{df}=4,26 ; P=0.045)$. The year effect was driven mainly by stem density (significantly greater in $2011 ; F=9.65 ; \mathrm{df}=1 ; P=0.004$ ) and site wetness (marginally wetter in $2011 ; F=6.80$; df $=1 ; P=0.014$ ), and the elevation effect was driven primarily by site wetness (not significant, but suggesting wetter at 
Table 3. Best linear regression model for predicting vole abundance at meadow sites where voles were present in the Sierra Nevada Mountains, California, in 2010 and 2011. All 25 other candidate models had $\Delta \mathrm{AIC}_{c}$ greater than two.

\begin{tabular}{|c|c|c|c|c|c|c|c|c|}
\hline \multirow[b]{2}{*}{ Variable } & \multirow[b]{2}{*}{$K^{\mathrm{a}}$} & \multicolumn{5}{|c|}{$\%$ Deviance } & \multicolumn{2}{|c|}{$95 \% \mathrm{CI}$} \\
\hline & & $\Delta \mathrm{AIC}_{c}^{\mathrm{b}}$ & $\mathrm{w}_{i}^{\mathrm{c}}$ & Explained & Coeff & $\mathrm{SE}$ & Lower & Upper \\
\hline & 3 & 0.00 & 0.28 & 7.79 & & & & \\
\hline Intercept & & & & & 5.73 & 1.13 & 3.51 & 7.95 \\
\hline Grazing & & & & & -2.13 & 1.49 & -5.06 & 0.80 \\
\hline
\end{tabular}

${ }^{\mathrm{a}} K=$ number of parameters

${ }^{\mathrm{b}} \Delta \mathrm{AIC}_{c}=$ difference between $\mathrm{AIC}_{c}$ of the model specified and the model with the lowest $\mathrm{AIC}_{c}$

${ }^{\mathrm{c}} \mathrm{W}_{i}=$ Akaike weight. Indicates the probability that the model specified is the best predictive model within the set of candidates 
Table 4. Best linear regression models for predicting gopher abundance at meadow sites in the Sierra Nevada Mountains, California, in 2010 and 2011. All 20 other candidate models had $\Delta \mathrm{AIC}_{c}$ greater than two.

\begin{tabular}{|c|c|c|c|c|c|c|c|c|}
\hline \multirow[b]{2}{*}{ Model } & \multirow[b]{2}{*}{$K^{\mathrm{a}}$} & \multicolumn{5}{|c|}{$\%$ Deviance } & \multicolumn{2}{|c|}{$95 \% \mathrm{CI}$} \\
\hline & & $\Delta \mathrm{AIC}_{c}{ }^{\mathrm{b}}$ & $w_{i}^{\mathrm{c}}$ & Explained & Coeff & SE & Lower & Upper \\
\hline Model One & 5 & 0.00 & 0.22 & 52.83 & & & & \\
\hline Intercept & & & & & 1.16 & 1.08 & -0.96 & 3.27 \\
\hline Wetness & & & & & -1.40 & 0.17 & -1.73 & -1.07 \\
\hline Stem density & & & & & 0.30 & 0.29 & -0.27 & 0.88 \\
\hline Frequency of forb & & & & & 2.10 & 1.24 & -0.33 & 4.53 \\
\hline Model Two & 4 & 0.66 & 0.16 & 50.78 & & & & \\
\hline Intercept & & & & & 2.79 & 0.50 & 1.81 & 3.76 \\
\hline Wetness & & & & & -1.37 & 0.17 & -1.71 & -1.04 \\
\hline Stem density & & & & & 0.45 & 0.28 & -0.10 & 1.01 \\
\hline Model Three & 6 & 0.96 & 0.14 & 53.79 & & & & \\
\hline Intercept & & & & & 2.56 & 0.50 & 1.58 & 3.55 \\
\hline Wetness & & & & & -1.38 & 0.17 & -1.72 & -1.04 \\
\hline Stem density & & & & & 0.46 & 0.29 & -0.10 & 1.02 \\
\hline Grazing & & & & & 0.23 & 0.22 & -0.20 & 0.66 \\
\hline $\begin{array}{l}\text { Corn lily } \\
\text { dominance }\end{array}$ & & & & & 0.41 & 0.25 & -0.08 & 0.91 \\
\hline
\end{tabular}


Table 4. Best linear regression models for predicting gopher abundance at meadow sites in the Sierra Nevada Mountains, California, in 2010 and 2011. All 20 other candidate models had $\Delta \mathrm{AIC}_{c}$ greater than two (continued).

\begin{tabular}{lcccccccc}
\hline & & \multicolumn{4}{c}{ \% Deviance } & & \multicolumn{3}{c}{$95 \%$ CI } \\
Model & $K^{\mathrm{a}}$ & $\Delta \mathrm{AIC}_{c}{ }^{\mathrm{b}}$ & $w_{i}{ }^{\mathrm{c}}$ & Explained & Coeff & $\mathrm{SE}$ & Lower & Upper \\
\hline Model Four & 5 & 1.39 & 0.11 & 51.89 & & & & \\
Intercept & & & & & & & & \\
Wetness & & & & 2.72 & 0.50 & 1.74 & 3.70 \\
Stem density & & & & -1.33 & 0.17 & -1.67 & -0.99 \\
Grazing & & & & 0.39 & 0.29 & -0.17 & 0.95 \\
& & & & & 0.27 & 0.22 & -0.16 & 0.70 \\
\hline
\end{tabular}

${ }^{\mathrm{a}} K=$ number of parameters

${ }^{\mathrm{b}} \Delta \mathrm{AIC}_{c}=$ difference between $\mathrm{AIC}_{c}$ of the model specified and the model with the lowest $\mathrm{AIC}_{c}$

${ }^{c} \mathrm{w}_{i}=$ Akaike weight. Indicates the probability that the model specified is the best predictive model within the set of candidates 
Table 5. Model-averaged linear regression model for predicting gopher abundance at meadow sites in the Sierra Nevada Mountains, California, in 2010 and 2011. Four candidate models that had $\Delta \mathrm{AIC}_{c}$ less than two were included in the model average (see Table 4 for original models).

\begin{tabular}{lcccc}
\hline & & \multicolumn{4}{c}{$95 \%$ CI } \\
Variable & Coefficient & SE & Lower & Upper \\
\hline Intercept & 2.15 & 0.70 & 0.77 & 3.53 \\
Wetness & -1.38 & 0.17 & -1.81 & -0.95 \\
Stem density & 0.39 & 0.29 & -0.17 & 0.96 \\
Grazing & 0.25 & 0.22 & -0.09 & 0.58 \\
Frequency of forbs & 2.10 & 1.24 & -0.33 & 4.53 \\
& & & & \\
Corn lily dominance & 0.41 & 0.25 & -0.08 & 0.91 \\
\hline
\end{tabular}

Model-averaged percent deviance explained $=52.35 \%$ 
higher elevations; $F=3.99 ; \mathrm{df}=1 ; P=0.055)$. Means and standard errors for vegetation variables, wetness, and soil temperature are provided in Table 6 . There was no significant difference in the frequency of corn lily dominance between grazed and ungrazed meadow sites $\left(\chi^{2}=0.18\right.$, df $\left.=1, P=0.673\right)$. 
Table 6. Means plus or minus one standard error for vegetation, wetness, and soil temperature at grazed and ungrazed meadow sites in the Sierra Nevada Mountains, California, in 2010 and 2011.

\begin{tabular}{|c|c|c|c|c|}
\hline \multirow[b]{2}{*}{ Variable } & \multicolumn{2}{|c|}{2010} & \multicolumn{2}{|c|}{2011} \\
\hline & $\begin{array}{l}\text { Grazed } \\
(n=17)\end{array}$ & $\begin{array}{l}\text { Ungrazed } \\
(\mathrm{n}=15)\end{array}$ & $\begin{array}{l}\text { Grazed } \\
(n=19)\end{array}$ & $\begin{array}{l}\text { Ungrazed } \\
(\mathrm{n}=19)\end{array}$ \\
\hline Max. veg. ht. (mm) & $198 \pm 22$ & $220 \pm 29$ & $195 \pm 25$ & $264 \pm 29$ \\
\hline Cover $(\%)$ & $60 \pm 5$ & $65 \pm 4$ & $57 \pm 4$ & $65 \pm 4$ \\
\hline Stem density ${ }^{\mathrm{a}}$ & $6 \pm 1$ & $6 \pm 1$ & $8 \pm 1$ & $7 \pm 0$ \\
\hline Sward height (mm) & $108 \pm 17$ & $91 \pm 11$ & $108 \pm 20$ & $112 \pm 11$ \\
\hline Frequency of grass ${ }^{b}$ & $0.33 \pm 0.07$ & $0.38 \pm 0.07$ & $0.50 \pm 0.07$ & $0.49 \pm 0.07$ \\
\hline Frequency of forb ${ }^{b}$ & $0.92 \pm 0.02$ & $0.92 \pm 0.03$ & $0.93 \pm 0.02$ & $0.91 \pm 0.02$ \\
\hline Frequency of sedge $e^{b}$ & $0.45 \pm 0.08$ & $0.44 \pm 0.07$ & $0.29 \pm 0.06$ & $0.37 \pm 0.07$ \\
\hline Frequency of rush ${ }^{b}$ & $0.02 \pm 0.01$ & $0.14 \pm 0.06$ & $0.11 \pm 0.04$ & $0.16 \pm 0.05$ \\
\hline Wetness $^{c}$ & $0.85 \pm 0.18$ & $0.92 \pm 0.18$ & $1.17 \pm 0.13$ & $1.43 \pm 0.16$ \\
\hline Soil temp. $\left({ }^{\circ} \mathrm{C}\right)$ & $14 \pm 1$ & $15 \pm 1$ & $14 \pm 1$ & $14 \pm 1$ \\
\hline
\end{tabular}

${ }^{\mathrm{a}}$ Stem density was the number of rooted plants within a $5 \mathrm{~cm}$ by $3.8 \mathrm{~cm}$ rectangle

${ }^{b}$ Frequency was the number of presences divided by the total number of samples at a site (42)

${ }^{c}$ Wetness was $0,1,2,3$, or 4 for dry, moist, saturated, or flooded respectively 


\section{DISCUSSION}

Vole abundance in this study appeared very low, but it was difficult to compare the abundance I observed to historical numbers because there have been no long-term mark/recapture studies on voles in meadows of the Sierra Nevada. Comparing abundance between studies was also difficult because detection probabilities have not been incorporated into density estimates (e.g., Jenkins 1948, Winter 1986, Reid 1989,

Greene 1995). With that said, a mark/recapture study found that abundance of montane voles and long-tailed voles ranged from 5 to 16 voles per hectare in three meadows of the Sierra Nevada during three summer seasons (Jenkins 1948). Another mark/recapture study that occurred late May to June 2009 reported no vole captures, but this study was short in duration and only four grazed and four ungrazed sites were surveyed (LaManna 2009). An anecdotal report from Yosemite National Park stated that during high vole abundance, vole runways were very numerous and voles were seen regularly when walking through meadows (Dunmire 1957). During the summers of 2010 and 2011, runways were very scarce and I observed only three voles while walking through all study sites. The potential for vole density in meadows of the Sierra Nevada is not fully understood, but density of the montane vole has reached 1811 to 7413 voles per hectare in cultivated landscapes of northern California and Oregon (Murray 1965).

Other attempts at estimating vole abundance in meadows of the Sierra Nevada have been based on sign (e.g., Winter 1986, Reid 1989, Greene 1995), but vole-sign indices have been unreliable because sign was small and difficult to detect (Gervais 2010). In addition, long-tailed voles have not usually constructed runways, and runways have been the most detectable form of sign when created by montane voles (Ingles 1965, 
Johnson and Johnson 1982, Smolen and Keller 1987). This difference in detection probability between species could bias estimates depending on the species composition in a meadow. In my study, long-tailed voles made up 56 percent of the total vole captures, and the two vole species co-occurred 19 percent of the time when at least one species was present. Therefore estimating vole abundance and habitat relationships based on the presence of runways may be very misleading in my study area. Trapping appeared to provide a better estimate of abundance because I captured voles in many sites where I saw no vole sign. Also, small mammal species were identified in-hand with very high confidence compared to sign-based procedures.

Trapping data indicated that vole abundance has been low in the central Sierra Nevada for three consecutive years (LaManna 2009, this study). Voles in other areas have undergone two to five year population cycles, but the length and predictability of vole populations cycles have not been studied in meadows of the Sierra Nevada (Nero 1980, Hilden and Helo 1981, Smolen and Keller 1987, Sera and Early 2003). Owl reproductive success is thought to fluctuate with the vole population cycle (Winter 1986), and was determined to be low in 2010 and 2011 (personal communication, J. Medley 2012. Pacific Southwest Research Station, 800 Buchanan Street, West Annex Building, Albany, California 94710) during the period I found low vole abundance. This relationship was consistent with the idea that voles are critical prey for great gray owl reproductive success and suggests the importance of considering vole habitat in meadow management.

The relative importance of voles or gophers to owl reproductive success has been debated, but it is clear that great gray owls have not reproduced well when vole and 
gopher abundance was low (Nero 1980, Hilden and Helo 1981, Winter 1986, Franklin 1988, Reid 1989, Bull and Henjum 1990, Greene 1995). Results from Reid (1989) suggested that the sum of voles and gophers was more important than any particular prey genera, while Winter (1986) suggested that reproduction was particularly correlated with vole abundance. Greene (1995) found that owl reproduction was positively correlated with soil moisture and marginally correlated with vole abundance. All three of these studies took place in the Sierra Nevada within a section of my study area. Franklin (1988) found that fledgling success increased with the proportion of gophers in owl diet, but Franklin's study was in Idaho and Wyoming and may have represented a very different system of predator-prey relationships.

I found a negative correlation between grazing and vole abundance in sites where voles were present in this study. This model was weak, but may indicate a pattern that would be more evident with greater vole abundance, heavier grazing, or a different study design. Because I was interested in the influence of current cattle grazing regimes on owl prey and vegetation during the owl nesting season, I surveyed meadows based on elevation and vegetation phenology rather than the seasonal timing of grazing. I was also interested in assessing regional patterns by maximizing spatial coverage rather than monitoring the response of small mammals to grazing on fewer sites with a before-after control-impact design. My sampling scheme led to several cases where grazed meadows were surveyed prior to the onset of grazing for that year, which may have explained the lack of vegetative differences between grazed and ungrazed sites. Other studies that monitored voles and grazing over longer periods of time found that voles were positively associated with greater physical vegetation features (e.g., cover and height) and 
negatively associated with grazing (Peles and Barrett 1996, Jacob and Hempel 2003, Johnson and Horn 2008). There may be a lag time to detect this response depending on grazing intensity, time of year, vole abundance, and preexisting meadow conditions (Johnson and Horn 2008). Future studies could focus on the within-season effect of grazing with a before-after control-impact design, but that design would only be effective if vole abundance was higher than it was during this study.

Given that vole presence was positively correlated with sward height, and that grazing should inherently reduce sward height in areas with palatable plant species, I recommend not grazing cattle when managing meadows for vole habitat. If grazing does take place, I suggest carefully monitoring grazing and sward height throughout the cattle grazing season. In sites not dominated by corn lily, I found that an average sward height (actual sward height, not log-transformed height) of $290 \mathrm{~mm}$ was necessary to yield a 90 percent predicted probability of presence, $193 \mathrm{~mm}$ for a 70 percent predicted probability of presence, and $149 \mathrm{~mm}$ for a 50 percent predicted probability of presence. Sites not dominated by corn lily never had an average sward height high enough to yield a predicted probability of presence greater than 74 percent, so obtaining a predicted probability of 90 percent based on sward height was hypothetical. In sites dominated by corn lily, an average sward height of $125 \mathrm{~mm}$ was necessary to yield a 90 percent predicted probability of presence, $83 \mathrm{~mm}$ for a 70 percent predicted probability of presence, and $64 \mathrm{~mm}$ for a 50 percent predicted probability of presence (Figure 5). The projections discussed only address sward heights resulting in probabilities of vole presence, so I recommend maintaining higher sward height values when managing habitat for vole abundance. Reliable vole abundance predictions could not be made from 


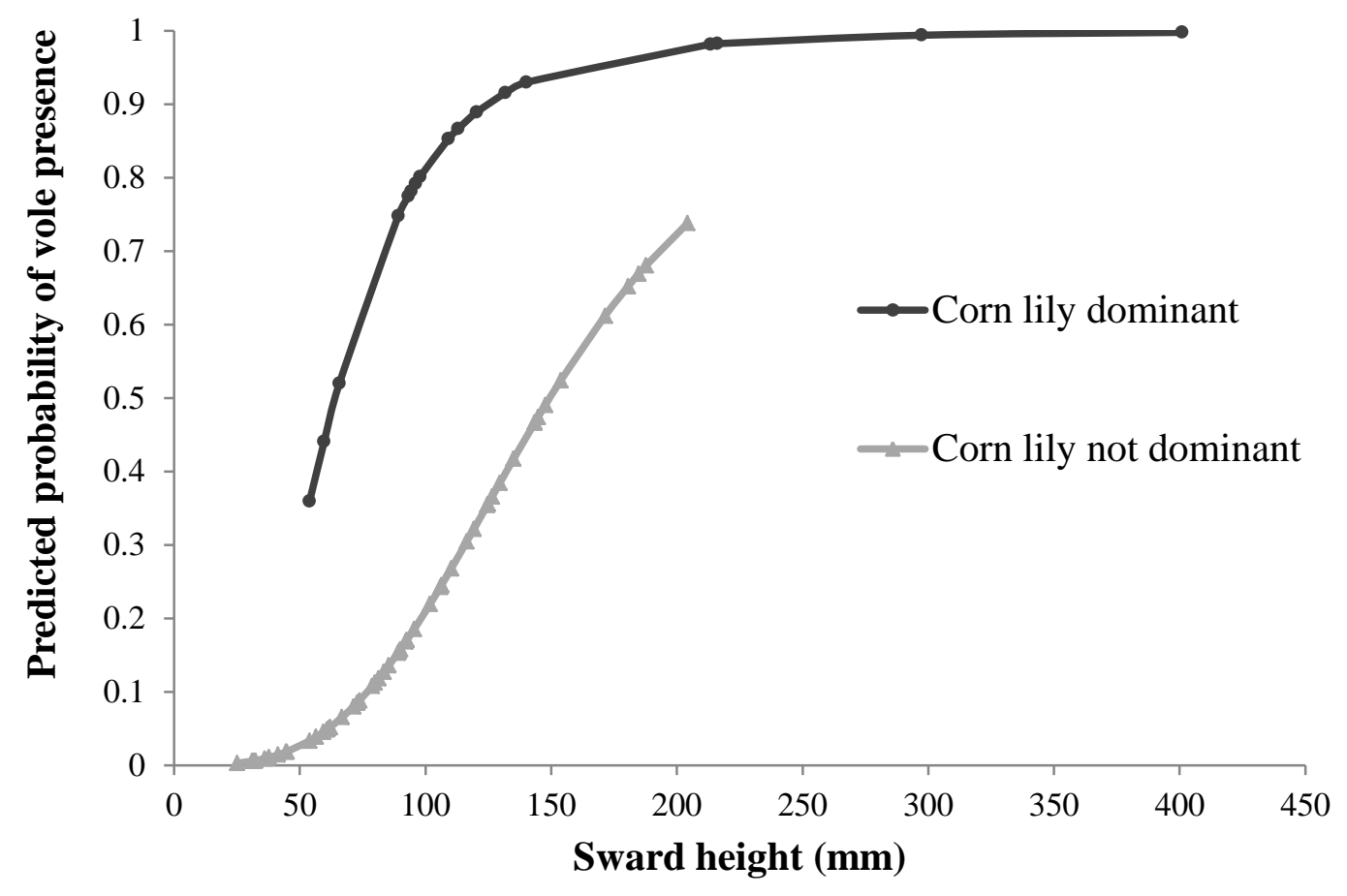

Figure 5. The influence of sward height on predicted probability of vole presence at corn lily dominated and non-corn lily dominated meadow sites in the Sierra Nevada Mountains, California, 2010 and 2011. Model-averaged coefficients from $k$-fold validation procedures and observed sward heights were used to obtain predicted values. 
this study because the percent deviance explained by the vole abundance model was only 7.79 percent. In addition to the statistical model projections, managers should consider that average sward height in sites where voles were present was $143( \pm 14) \mathrm{mm}$ while average sward height in sites where voles were absent was $84( \pm 7) \mathrm{mm}$.

If considering the sward heights discussed for managing vole habitat, managers should realize that the modeled relationships have not been tested over time and space. With that said, sward heights that resulted in a greater than 50 percent probability of vole presence in non-corn lily dominated sites and a 90 percent probability in corn lily dominated sites were similar to guidelines from Beck (1985) and findings in Greene (1995). Beck (1985) required a minimum ungrazed herbaceous vegetation height of 127 mm with $254 \mathrm{~mm}$ preferred for meadows with Great Gray Owls. The Beck (1985) guidelines were used in the Stanislaus National Forest at Ackerson Meadows and were shown to be compatible with successful Great Gray Owl reproduction. Greene (1995) found that voles occurred more often than expected at plots with greater than $300 \mathrm{~mm}$ of vegetation height and that plots with voles present had an average vegetation height of $480 \mathrm{~mm}( \pm 22)$. Managers should note that vegetation height and sward height are not equivalent. Sward height will typically be lower than vegetation height because a plate is dropped on the vegetation for sward height measurements. I recommend using sward height when managing for vole habitat because vegetation height and density are incorporated into sward height, and tall but sparse vegetation may not provide voles with sufficient cover from predators (Birney et al. 1976, Greene 1995).

Though the probability of vole presence increased with corn lily dominance, corn lily has been toxic to most herbivores and was not consumed by long-tailed voles and 
montane voles in an experiment (Cervantes 1992). Corn lily may have also reduced the availability of food for voles by shading-out nutritious plants. During my study, I observed anecdotally that plants were less abundant under corn lily compared to areas where corn lily was absent. Several studies have suggested that vole population declines may have been initiated during high vole density by limited food availability from competition and an associated increase in the consumption of non-preferred toxic plants (Birney et al. 1976, Jensen and Doncaster 1999, Kent et al. 2005). Therefore if corn lily may limit nutritious plant availability, expansive corn lily may have some deleterious effects on voles, particularly when vole abundance is high. However, the presence of corn lily may benefit voles by providing cover from predators.

The probability of vole presence increased with corn lily and sward height, but it is unclear if corn lily height and robustness may reduce owl foraging success beyond a certain threshold. Greene (1995) found that owls foraged most often in sites that correlated with vole habitat (taller vegetation, higher vegetation cover, and wetter soil) but that owl presence decreased when vegetation was very tall (500 to $750 \mathrm{~mm}$ ). This relationship seemed to suggest that optimal vegetation height for great gray owl foraging involved both prey availability (capability of an owl to make a capture given prey presence) and prey abundance.

Gopher abundance in this study was positively correlated with grazed meadows (though the 95 percent confidence interval for the coefficient of grazing included zero which indicated a weak relationship) and was associated with other features like dryness and the frequency of forb presence (though the 95 percent confidence interval for forb presence included zero) which have been correlated with grazing (Gifford and Hawkins 
1978). Powers et al. (2011) also found that gophers were denser in grazed, rather than ungrazed meadows of the Sierra Nevada. When interpreting these results, it is important to consider the potential influence of grazing intensity. Grazing intensity was not incorporated into this study because grazing intensity was difficult to quantify given the high degree of variation in cattle numbers, grazing duration, and cattle onset date from year to year (Gillen et al. 1984, McIlroy et al. 2011). However, other researchers have found lower gopher abundance in grazed sites and suggested that high intensity grazing may have reduced forage quality and burrowing capability due to soil compaction (Phillips 1936, Hunter 1991). There may have been a positive relationship between gopher abundance and grazing intensity to a certain threshold at which point the relationship became negative. In my study, gophers were positively associated with grazed sites, but also with stem density (though the 95 percent confidence interval for stem density included zero). Stem density did not differ significantly between grazed and ungrazed sites in this study, but has decreased with high intensity grazing in other studies (Blydenstein et al. 1957, Vankat and Major 1978). Therefore, increased grazing intensity in my study area may have unpredictable results.

I observed a 62 percent decrease in the number of gophers per plot from 2010 to 2011. This may have been caused by the increase in meadow site wetness from 2010 to 2011, and the associated negative correlation between gopher abundance and wetness (Figure 6). This negative association with wetness was consistent with several other studies of gopher habitat relationships (Ingles 1952, Greene 1995, Jones and Baxter 2004). Because gopher abundance in this study was indexed from fresh mounds, it was possible that gopher activity, not gopher density, changed over the two years. However, 


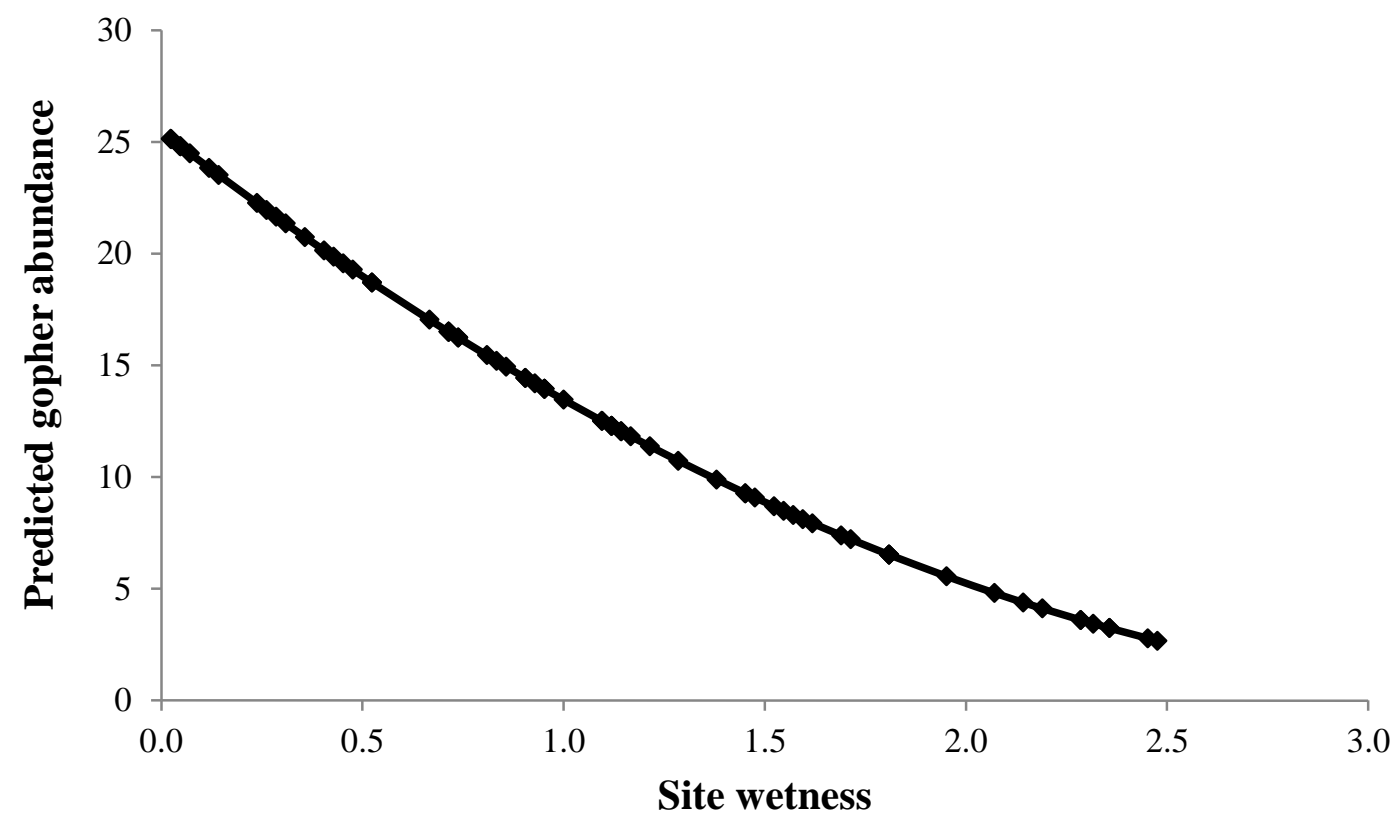

Figure 6. The influence of site wetness on predicted gopher abundance at meadow sites in the Sierra Nevada Mountains, California, in 2010 and 2011. Model-averaged coefficients from competitive linear regression models $\left(\triangle \mathrm{AIC}_{c}\right.$ less than two) were used with observed wetness values to obtain predicted abundance. All other variables from the model-average were held constant at their respective averages. 
gopher mound surveys have successfully represented gopher abundance in other studies (e.g., Reid et al. 1966), and Ingles (1952) found that radio-marked gophers have shifted their home range from a saturated area to a drier area prior to snow melt.

When managing meadows for great gray owls, the habitat relationships of owl prey and other factors that have influenced owl productivity should be considered. Prior research found a positive correlation between great gray owl reproduction and ungrazed meadow conditions (Greene 1995), and Yosemite National Park was ungrazed and found to have a much higher density of great gray owls than adjacent National Forests (Sears 2006). Given the high proportion of grazed meadows in National Forests, less cattle grazing may increase great gray owl productivity and result in greater owl density as found in adjacent Yosemite National Park (Sears 2006). Fewer grazed meadows may also increase owl productivity because the effects of cattle on great gray owl foraging success are poorly understood, and there may be potential for negative impacts. Regardless of prey abundance, cattle presence may cause prey to become more skittish and less available, and cattle may disturb owls from noise (actual cattle noise and bells) or physical blockading. I suggest a study investigating the influence of cattle presence on great gray owl hunting success in order to better understand these potential impacts.

The habitat relationships of both voles and gophers should be considered when managing meadows for great gray owls. I recommend that voles be the focus of management because voles were less prevalent than gophers in my study, and some literature from the Sierra Nevada has suggested that owl reproduction was linked to a diet abundant in voles (e.g., Winter 1986) and meadow conditions associated with vole habitat and abundance (e.g., Greene 1995). With that said, gophers have been important 
prey species that may have increased great gray owl survival when vole density was low, so gopher habitat relationships should still be considered (Winter 1986, Reid 1989).

The differences found between vole and gopher habitat relationships could lead to different scenarios when managing meadows for great gray owls. One option could be to spatially allocate grazed and ungrazed meadows, especially near historic or active owl nests, such that owls could have access to both. The benefits of this arrangement may last several years because great gray owls typically exhibit high nest-site fidelity and will forage in the same meadows for multiple years (Winter 1986). Another option suitable for managing large meadows could be to allocate grazed and ungrazed zones within a meadow. Managers could adjust the density of cattle, and/or the grazing duration, and/or the onset date to better manage sward height for great gray owl prey throughout the cattle grazing season. Lastly, management may be most efficient by prioritizing wet meadow sites for voles since gophers were not likely to be abundant in wet sites, and vole abundance has been correlated with moist soils (Smolen and Keller 1987, Greene 1995, Sera and Early 2003). Therefore particularly in areas with moist soils, I recommend maintaining sward height commensurate with the habitat relationships of voles found in this study. 


\section{LITERATURE CITED}

Armour, C. L., D. A. Duff, and W. Elmore. 1991. Effect of livestock grazing on riparian ecosystems. Fisheries 16:7-11.

Beck, T.W. 1985. Interim direction for management of great gray owl. United States Department of Agriculture, Forest Service, Stanislaus National Forest, Sonora, California, USA.

Beck, T. W., and J. Winter. 2000. Survey protocol for the great gray owl in the Sierra Nevada of California. United States Department of Agriculture, Forest Service, Pacific Southwest Region, Vallejo, California, USA.

Birney, E. C., W. E. Grant, and D. D. Baird. 1976. Importance of vegetative cover to cycles of Microtus populations. Ecology 57:1043-1051.

Blydenstein, J., C.R. Hungerford, G.I. Day, and R.R. Humphrey. Effect of domestic livestock exclusion on vegetation in the Sonoran Desert. Ecology 38:522-526.

Buckland, S. T., D. R. Anderson, K. P. Burnham, J. L. Laake, K. L. Borchers, and L Thomas. 2004. Advanced distance sampling. Oxford University Press, Oxford, UK.

Bull, E. L., and M. G. Henjum. 1990. Ecology of the great gray owl. United States Department of Agriculture, Forest Service, Pacific Northwest Region, La Grande, Oregon, USA.

Burnham, K.P., and D.R. Anderson. 2002. Model selection and multimodel inference: a practical information-theoretic approach. Springer-Verlag, New York, New York, USA. 
California Department of Fish and Game. 2011. State and federally listed endangered and threatened animals of California. California Department of Fish and Game, Sacramento, California, USA.

Cervantes, F.A. 1992. Differential use of food in captivity by the voles Microtus montanus and M. longicaudus (Rodentia: Arvicolidae). Anales del Instituto de Biología. Serie Zoología 63:287-291.

Dunmire, W. 1957. Mice in our meadows. Yosemite Nature Notes 36:105-107.

Fielding, A.H., and J.F. Bell. 1997. A review of methods for the assessment of prediction errors in conservation presence/absence models. Environmental Conservation 24:38-49.

Franklin, A.B. 1988. Breeding biology of the great gray owl in southeastern Idaho and northwestern Wyoming. The Condor 90:689-696.

Gillen, R.L., W.C. Krueger, and R.F. Miller. 1984. Cattle distribution on mountain rangeland in northeastern Oregon. Journal of Range Management 37:549-553.

Gervais, J.A. 2010. Testing sign indices to monitor voles in grasslands and agriculture. Northwest Science 84:282-288.

Getz, L. L., B. McGuire, J. E. Hofmann, T. Pizzuto, and B. Frase. 1994. Natal dispersal and philopatry in prairie voles (Microtus ochrogaster): settlement, survival, and potential reproductive success. Ethology, Ecology, and Evolution 6:267-284.

Getz, L. L., M. K. Oli, J. E. Hofmann, B. McGuire, and A. Ozgul. 2005. Factors influencing movement distances of two species of sympatric voles. Journal of Mammalogy 86:647-654. 
Gifford, G. F., and D. Hawkins. 1978. Hydrologic impact of grazing on infiltration: a critical review. Water Resources Research 14:305-313.

Greene, C. 1995. Habitat requirements of great gray owls in the central Sierra Nevada. Master's Thesis, University of Michigan, Ann Arbor, Michigan, USA.

Hilden, O., and P. Helo. 1981. The great gray owl Strix nebulosa: a bird of the northern taiga. Ornis Fennica 58:159-166.

Hull, J.M., J.J. Keane, W.K. Savage, S.A. Godwin, J.A. Shafer, E.P. Jepsen, R. Gerhardt, C. Stermer, H.B. Ernest. 2010. Range-wide genetic differentiation among North American great gray owls (Strix nebulosa) reveals a distinct lineage restricted to the Sierra Nevada, California. Molecular Phylogenetics and Evolution 56:212221.

Hunter, J. E. 1991. Grazing and pocket gopher abundance in a California annual grassland. The Southwestern Naturalist 36:117-118.

Ingles, L.G. 1952. The ecology of the mountain pocket gopher, Thomomys monticola. Ecology 88:87-95.

Ingles, L.G. 1965. Mammals of the pacific states. Stanford University Press, Stanford, California, USA.

Jacob, J., and M. Hempel. 2003. Effects of farming practices on spatial behavior of common voles. Journal of Ethology 21:45-50.

Jenkins, H.O. 1948. A population study of the meadow mice (Microtus) in three Sierra Nevada meadows. Proceedings of the California Academy of Sciences 26:43-67. 
Jensen, S.P., and C.P. Doncaster. 1999. Lethal toxins in non-preferred foods: how plant chemical defenses can drive microtine cycles. Journal of Theoretical Biology 199:63-85.

Johnson, M. D., and C. M. Horn. 2008. Effects of rotational grazing on rodents and raptors on a coastal grassland. Western North American Naturalist 68:444-452.

Johnson, M.L., and S. Johnson. 1982. Voles. In wild mammals of North America. J.A. Chapman and G.A. Feldhammer (editors). John Hopkins University Press, Baltimore, Maryland, USA.

Johnston, A.N., and R.G. Anthony. 2008. Small-mammal microhabitat associations and response to grazing in Oregon. Journal of Wildlife Management 72:1736-1746.

Jones, C.A., and C.N. Baxter. 2004. Thomomys bottae. Mammalian species 742:1-14.

Kent, A., S.P. Jensen, and C.P. Doncaster. 2005. Model of microtine cycles caused by lethal toxins in non-preferred food plants. Journal of Theoretical Biology. 234:593-604.

Klaus, M., R. E. Moore, and E. Vyse. 1999. Impact of precipitation and grazing on the water vole in the Beartooth Mountains of Montana and Wyoming, USA. Arctic, Antarctic, and Alpine Research 31:278-282.

LaManna, J.A. 2009. Grazing effects on prey populations of great gray owl in the central Sierra Nevada. Investigator's Annual Report, United States Department of the Interior, National Park Service, Washington, DC, USA.

McIlroy, S.K., B.H. Allen-Diaz, and A.C. Berg. 2011. Using digital photography to examine grazing in montane meadows. Rangeland Ecology and Management 64:187-195. 
McKelvey, K., and D. E. Pearson. 2001. Population estimation with sparse data: the role of estimators versus indices revisited. Canadian Journal of Zoology 79:17541765.

Moritz, C., J.L. Patton, C.J. Conroy, J.L. Parra, G.C. White, and S.R. Beissinger. 2008. Impact of a century of climate change on small-mammal communities in Yosemite National Park, USA. Science 322:261-264.

Murray, K.F. 1965. Population changes during the 1957-1958 vole (Microtus) outbreak in California. Ecology 46:163-171.

Nero, R. W. 1980. The great gray owl: phantom of the northern forest. Smithsonian Press, Washington, DC, USA.

Parmenter, R. R., T. L. Yates, D. R. Anderson, K. P. Burnham, J. L. Dunnum, A. B. Franklin, M. T. Friggens, B. C. Lubow, M. Miller, G. S. Olson, C. A. Parmenter, J. Pollard, E. Rexstad, T. M. Shenk, T. R. Stanley, and G. C. White. 2003. Small-mammal density estimation: a field comparison of grid-based vs. webbased density estimators. Ecological Monographs 73:1-26.

Peles, J. D., and G. W. Barrett. 1996. Effects of vegetative cover on the population dynamics of meadow voles. Journal of Mammalogy 77:857-869.

Phillips, P. 1936. The distribution of rodents in overgrazed and normal grasslands of central Oklahoma. Ecology 17:673-679.

Potter, D. A. 2005. Riparian plant community classification: west slope, central and southern Sierra Nevada, California. United States Department of Agriculture, Forest Service, Pacific Southwest Region, Vallejo, California, USA. 
Powers, B., M.D. Johnson, J.A. LaManna, and A. Rich. 2011. The influence of cattle grazing on pocket gophers in the central Sierra Nevada Mountains, California: potential implications for great gray owls. Northwestern Naturalist 92:13-18.

Reid, V.H., R.M. Hansen, and A.L. Ward. 1966. Counting mounds and earth plugs to census mountain pocket gophers. Journal of Wildlife Management 30:327-334.

Reid, M. E. 1989. The predator-prey relationships of the great gray owl in Yosemite National Park. Cooperative National Park Resources Studies Unit Report 35, Davis, California, USA.

van Riper, C., III., and J. van Wagtendonk. 2006. Home range characteristics of great gray owls in Yosemite National Park, California. Journal of Raptor Research 40:130-141.

Schmidt, N. M., H. Olsen, M. Bildsoe, V. Sluydts, and H. Leirs. 2005. Effects of grazing intensity on small mammal population ecology in wet meadows. Basic and Applied Ecology 6:57-66.

Sears, C.L. 2006. Assessing distribution, habitat suitability, and site occupancy of great gray owls (Strix nebulosa) in California. Master's Thesis, University of California Davis, Davis, California, USA.

Sera, W. E., and C. N. Early. 2003. Microtus montanus. Mammilian Species 716:1-10. Smolen, M.J., and B.L. Keller. 1987. Microtus longicaudus. Mammalian Species 271:1-7.

United States Department of Agriculture. 2004. Sierra Nevada forest plan amendment final supplemental environmental impact statement and record of decision, 
biological opinion, assessment, and evaluation. United States Department of Agriculture, Forest Service, Pacific Southwest Region, Vallejo, California, USA.

Vankat, J.L., and J. Major. 1978. Vegetation changes in Sequoia National Park, California. Journal of Biogeography 5:377-402.

Western Regional Climate Center. 2012. National Oceanic and Atmospheric Administration cooperative climate summaries, Cherry Valley Dam, California, http:/www.wrcc.dri.edu/, 05/21/2012.

White, G. C., D. R. Anderson, K. P. Burnham, and D. L. Otis. 1982. Capture-recapture and removal methods for sampling closed populations. Publication LA-8787NERP. Los Alamos National Laboratory, Los Alamos, New Mexico, USA.

Winter, J. 1981. Some aspects of the ecology of the great gray owl in the Sierra Nevada. Investigator's report, United States Department of Agriculture, Forest Service, Stanislaus National Forest, Sonora, California, USA.

Winter, J. 1982. Further investigations on the ecology of the great gray owl in the central Sierra Nevada. Investigator's report, United States Department of Agriculture, Forest Service, Stanislaus National Forest, Sonora, California, USA.

Winter, J. 1986. Status, distribution, and ecology of the great gray owl (Strix nebulosa) in California. Master's Thesis, San Francisco State University, San Francisco, California, USA. 